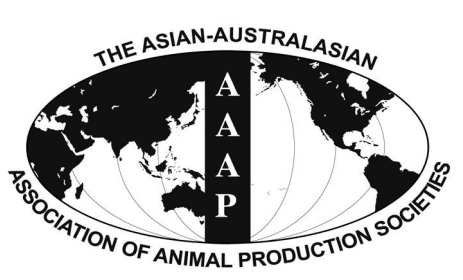

Open Access

Asian Australas. J. Anim. Sci.

Vol. 29, No. 8 : 1095-1101 August 2016

http://dx.doi.org/10.5713/ajas.15.0678

www.ajas.info

pISSN 1011-2367 elSSN 1976-5517

\title{
Ginsenoside Rg1 Improves In vitro-produced Embryo Quality by Increasing Glucose Uptake in Porcine Blastocysts
}

\author{
Seung-Hun Kim ${ }^{1}$, Kwang-Hwan Choi ${ }^{1}$, Dong-Kyung Lee ${ }^{1}$, Jong-Nam $\mathrm{Oh}^{1}$, \\ Jae Yeon Hwang ${ }^{1,2}$, Chi-Hun Park ${ }^{3}$, and Chang-Kyu Lee ${ }^{1,3, *}$ \\ ${ }^{1}$ Department of Agricultural Biotechnology, Animal Biotechnology Major, \\ and Research Institute of Agriculture and Life Science, Seoul National University, Seoul 151-921, Korea
}

\begin{abstract}
Ginsenoside $\operatorname{Rg} 1$ is a natural compound with various efficacies and functions. It has beneficial effects on aging, diabetes, and immunity, as well as antioxidant and proliferative functions. However, its effect on porcine embryo development remains unknown. We investigated the effect of ginsenoside $\mathrm{Rg} 1$ on the in vitro development of preimplantation porcine embryos after parthenogenetic activation in high-oxygen conditions. Ginsenoside treatment did not affect cleavage or blastocyst formation rates, but did increase the total cell number and reduced the rate of apoptosis. In addition, it had no effect on the expression of four apoptosisrelated genes (Bcl-2 homologous antagonist/killer, B-cell lymphoma-extra large, Caspase 3, and tumor protein p53) or two metabolism-related genes (mechanistic target of rapamycin, carnitine palmitoyltransferase 1B), but increased the expression of Glucose transporter 1 (GLUT1), indicating that it may increase glucose uptake. In summary, treatment with the appropriate concentration of ginsenoside $\mathrm{Rg} 1(20 \mu \mathrm{g} / \mathrm{mL})$ can increase glucose uptake, thereby improving the quality of embryos grown in highoxygen conditions. (Key Words: Ginsenoside Rg1, In vitro Culture, Metabolism, Embryo, Pig)
\end{abstract}

\section{INTRODUCTION}

Reactive oxygen species (ROS) can induce embryo damage through oxidative stress, including two-cell block by lipid peroxidation, enzyme inactivation, nuclear DNA fragmentation, mitochondrial damage, adenosine triphosphate (ATP) depletion, and embryo apoptosis. ROS are generated during oxidative phosphorylation, and are removed by non-enzymatic (e.g., antioxidant vitamins) and enzymatic defense systems (e.g., superoxide dismutase) (reviewed in [Guerin et al., 2001]). They occur more frequently in high-oxygen environments (Goto et al., 1993),

\footnotetext{
* Corresponding Author: Chang-Kyu Lee. Tel: +82-2-880-4805, Fax:+82-2-873-4805, E-mail: leeck@snu.ac.kr

2 Department of Animal Life Science, Kangwon National University, Chuncheon 200-701, Korea.

3 Designed Animal and Transplantation Research Institute, Institute of Green Bio Science and Technology, Seoul National University, Pyeongchang 232-916, Korea.

Submitted Aug. 15, 2015; Revised Oct. 1, 2015; Accepted Oct. 16, 2015
}

which typically have insufficient defense mechanisms to prevent ROS-induced damage (Kitagawa et al., 2004).

The reduction of ROS is important for preventing oxidative damage to embryos in vitro. To this end, studies have suggested that using co-culture systems to reduce oxygen concentrations from $20 \%$ to $5 \%$ during in vitro embryo development (Kitagawa et al., 2004), and decreasing light exposure (Goto et al., 1993) can protect embryos against oxidative stress. In addition, various methods of treatment, including the addition of antioxidants (e.g., resveratrol, a natural antioxidant) to porcine embryo cultures, have also shown promise in reducing oxidative stress (Kitagawa et al., 2004; Lee et al., 2010a). Ginsenoside is a major pharmacological component of ginseng ( $\mathrm{Lu}$ et al., 2009), and can be divided into two groups: $\mathrm{Rb} 1$ and $\mathrm{Rg} 1$. Ginsenoside $\mathrm{Rg} 1$, from Panax ginseng C. A. Meyer, has various pharmacological actions and multiple effects in vivo, including anti-diabetic (Xie et al., 2005), anti-amnestic (Mook-Jung et al., 2001), and immunity-boosting effects (Kenarova et al., 1990), as well 
as antioxidant (Chen et al., 2003) and proliferative activities (Shi et al., 2009). However, its effects on embryo development have not been investigated.

In this study, we investigated the effects of ginsenoside $\mathrm{Rg} 1$ on in vitro porcine embryo development. To this end, we used in vitro-produced parthenogenetic-activated porcine embryos, and analyzed the effects of ginsenoside $\mathrm{Rg} 1$ on the total cell number and rates of cleavage, formation, and apoptosis of blastocysts. The mechanisms underlying these effects were also examined. Surprisingly, ginsenoside $\operatorname{Rg} 1$ improved porcine embryo quality, not through antioxidant function, but by stimulating metabolic pathways, particularly the glucose uptake pathway.

\section{MATERIALS AND METHODS}

\section{Animal welfare}

The authors assert that all procedures contributing to this work comply with the ethical standards of the relevant national and institutional guides on the care and use of laboratory animals. The care and experimental use of pigs was approved by the Institute of Laboratory Animal Resources, Seoul National University (SNU-140328-2).

\section{Chemicals}

Ginsenoside $\operatorname{Rg} 1$ (purity $\geq 98 \%$ by high performance liquid chromatography) was purchased from Ambo Institute (Daejeon, Korea), and stored at $-20^{\circ} \mathrm{C}$ until use. It was mixed with porcine zygote medium 3 (PZM-3), and diluted before use. All of the chemicals were purchased from Sigma-Aldrich Corp. (St. Louis, MO, USA) unless otherwise stated.

\section{Oocyte collection and in vitro maturation}

Porcine ovaries, donated by the Sooam Biotech Research Institute (Seoul, Korea), were used. Porcine follicular fluid (PFF) and cumulus-oocyte complexes (COCs) were aspirated using a syringe and 18-gauge needle. Sediments were washed twice with Tyrodes lactate-Hepes medium supplemented with $0.01 \%$ polyvinyl alcohol (TLHepes-PVA). Oocytes with compact cumulus cells and granulated cytoplasm were selected for in vitro maturation (IVM). Selected COCs were washed twice with TL-HepesPVA medium and cultured in IVM medium (TCM-199; Life Technologies, Rockville, MD, USA) supplemented with 10 $\mathrm{ng} / \mathrm{mL}$ epidermal growth factor, $1 \mu \mathrm{g} / \mathrm{mL}$ insulin, and $10 \%$ (v/v) PFF for $44 \mathrm{~h}$ at $39^{\circ} \mathrm{C}$ in $5 \% \mathrm{CO}_{2}$ and humidified conditions. COCs were treated with hormones, $4 \mathrm{IU} / \mathrm{mL}$ equine chorionic gonadotropin (eCG; Intervet, Cambridge, $\mathrm{UK}$ ), and human chorionic gonadotropin (hCG; Intervet, UK) for the first $22 \mathrm{~h}$, and then were maturated in hormonefree conditions for the last $22 \mathrm{~h}$. After $44 \mathrm{~h}$ of maturation, oocytes were isolated from cumulus cells using $0.1 \%(\mathrm{w} / \mathrm{v})$ hyaluronidase. Cumulus-free oocytes were washed twice with Dulbecco's phosphate-buffered saline (DPBS; Welgene, Daegu, Korea) supplemented with $0.4 \%$ (w/v) bovine serum albumin (BSA).

\section{Parthenogenetic activation}

Cumulus-free oocytes were placed in an electrode chamber, and electronically activated by an electric pulse $(1.0 \mathrm{kV} / \mathrm{cm}$ for $60 \mu \mathrm{s})$ in activation solution $(280 \mathrm{mM}$ mannitol, $\left.0.01 \mathrm{mM} \mathrm{CaCl}, 0.05 \mathrm{mM} \mathrm{MgCl}_{2}\right)$ using a BTX Electro cell manipulator ECM2001 (BTX, San Diego, CA, USA). Parthenogenetic-activated oocytes were washed twice with $0.4 \%$ (w/v) BSA-supplemented DPBS (Welgene, Korea), followed by a $4 \mathrm{~h}$ incubation in PZM-3-containing $2 \mathrm{mmol} / \mathrm{L} 6$-dimethylaminopurin for post-activation.

\section{In vitro culture and ginsenoside $\mathrm{Rg} 1$ treatment}

Post-activated oocytes were cultured in drops of PZM-3 covered with mineral oil for $168 \mathrm{~h}$. Embryo culture conditions were maintained at $39^{\circ} \mathrm{C}$ in a humidified atmosphere, $5 \% \mathrm{CO}_{2}$, and $5 \% \mathrm{O}_{2}$ for the positive control group, and $20 \% \mathrm{O}_{2}$ for the treatment and negative control groups. Ginsenoside $\operatorname{Rg} 1$ was used at concentrations of 5, 10,20 , and $50 \mu \mathrm{g} / \mathrm{mL}$. The cleavage rate was calculated between 48 to $72 \mathrm{~h}$. The number of blastocysts and the rate of blastocyst formation were calculated $168 \mathrm{~h}$ after parthenogenetic activation.

\section{Cell counts and apoptosis measurements}

Blastocysts cultured for $168 \mathrm{~h}$ were fixed in $4 \%(\mathrm{w} / \mathrm{v})$ paraformaldehyde for $1 \mathrm{~h}$. After fixation, an in situ cell death detection kit (Roche, Mannheim, Germany) was used in a terminal deoxynucleotidyltransferase (TdT)-mediated deoxy-uridine nick-end labeling (TUNEL) assay according to the manufacturer's instructions. Then, blastocysts were stained with $5 \mathrm{mg} / \mathrm{mL}$ bisbenzimide (Hoechst 33342) for 5 min. Total cell numbers and apoptosis rates for blastocysts were calculated after staining under a UV light using a micromanipulator (eclipse TE2000-U; Nikon, Tokyo, Japan).

\section{Analysis of mRNA expression by quantitative real-time polymerase chain reaction}

The zona pellucida of unhatched blastocysts was removed with acidified Tyrode's solution before mRNA extraction. mRNA was extracted from embryos using a Dynabeads mRNA Direct Kit (Life Technologies, USA), according to the manufacturer's instructions. cDNA synthesis was performed using a High Capacity RNA-tocDNA (cDNA Reverse Transcription) Kit (Applied Biosystems; ABI, Foster City, CA, USA), according to the 
Table 1. Primer sequences, product sizes, and accession numbers used for gene expression analysis

\begin{tabular}{|c|c|c|c|}
\hline$\overline{\mathrm{mRNA}}$ & Primer sequences $\left(5^{\prime}-3^{\prime}\right)$ & Product size (base pair) & Gene access number \\
\hline$A C T B$ & $\begin{array}{l}\mathrm{F}: \text { TCCCTGGAGAAGAGCTACGA } \\
\mathrm{R}: \text { CGCACTTCATGATCGAGTTG }\end{array}$ & 154 & U07786.1 \\
\hline$B A K 1$ & $\begin{array}{l}\mathrm{F}: \text { CAGCCGACAGCGGAAAAC } \\
\mathrm{R}: \text { GGTAGCCAAAGCCCAGAAGA }\end{array}$ & 109 & AJ001204.1 \\
\hline$B c l-x L$ & $\begin{array}{l}\text { F : ACTGTGCGTGGAGAGCGTAG } \\
\text { R : AGGTGGTCATTCAGGTAAGTGG }\end{array}$ & 87 & AF216205.1 \\
\hline CASP3 & $\begin{array}{l}\mathrm{F}: \text { GAACTCTAACTGGCAAACCCAA } \\
\mathrm{R}: \text { CACTGTCCGTCTCAATCCCA }\end{array}$ & 84 & AB029345.1 \\
\hline TP53 & $\begin{array}{l}\mathrm{F}: \text { CCCATCCTCACCATCATCAC } \\
\mathrm{R}: \text { GCACAAACACGCACCTCAA }\end{array}$ & 80 & NM_213824.3 \\
\hline GLUT1 & $\begin{array}{l}\mathrm{F}: \text { GCTTCCAGTATGTGGAGCAACT } \\
\mathrm{R}: \text { AAGCAATCTCATCGAAGGTCC }\end{array}$ & 119 & XM_005665507.1 \\
\hline$m T O R$ & $\begin{array}{l}\mathrm{F}: \text { CGCCTGAACACGTGGTAATAGA } \\
\mathrm{R}: \text { CAGGCATACGGTCGAGACTTAA }\end{array}$ & 116 & XM_003127584 \\
\hline CPTIB & $\begin{array}{l}\mathrm{F}: \text { GCACGCCAGGCCTTCTTCAGC } \\
\mathrm{R}: \text { TGGCCTCGTCTTCCGGGTCATAGT }\end{array}$ & 121 & NM_001007191.1 \\
\hline
\end{tabular}

manufacturer's instructions. Briefly, at a final volume of 20 $\mu \mathrm{L}$, cDNA synthesis was performed at $37.5^{\circ} \mathrm{C}$ for $60 \mathrm{~min}$, and samples were subsequently incubated at $95^{\circ} \mathrm{C}$ for $5 \mathrm{~min}$ to activate the reverse transcription reaction. Synthesized cDNA samples were stored at $-80^{\circ} \mathrm{C}$ until subsequent use. Quantitative real-time polymerase chain reaction (qPCR) was performed using an ABI 7300 Real-Time PCR System (Applied Biosystems, USA). A DyNAmo HS SYBR Green qPCR Kit (Thermo scientific, Rockford, IL, USA) was used for real-time quantification of the PCR products. For amplification, $0.1 \mu \mathrm{M}$ of each primer listed in Table 1 and $0.5 \mu \mathrm{L}$ blastocyst cDNA were added to the $10 \mu \mathrm{L}$ reaction mixture. The reactions were performed under the following conditions: 1 cycle at $95^{\circ} \mathrm{C}$ for $10 \mathrm{~min} ; 40$ cycles at $95^{\circ} \mathrm{C}$ for $15 \mathrm{~s}$; and $60 \mathrm{~s}$ at annealing temperature. The dissociation curve was analyzed to confirm the specificity of the PCR product. Beta-actin was used as a control gene to determine the relative quantity. All of the genes were measured in triplicate, and relative expression ratios were analyzed by the $2^{-\Delta \Delta} \mathrm{Ct}$ (threshold cycle) method (Livak and Schmittgen, 2001).

\section{Statistical analysis}

All of the data were analyzed using the GraphPad Prism statistical program (GraphPad Software, San Diego, CA, USA). Cleavage rate, blastocyst formation rate, total cell number, and apoptosis rate were analyzed using one-way analysis of variance (ANOVA) and Dunnett's test. qPCR data were analyzed using ANOVA and Fisher's least significant difference. All of the data are reported as means \pm standard errors of the mean. $p$ values less than 0.05 were considered statistically significant.

\section{RESULTS}

Effects of $\mathrm{O}_{2}$ concentration and ginsenoside $\mathrm{Rg} 1$ on parthenote cleavage and blastocyst formation rates

Porcine parthenotes were divided into six groups including two control groups grown under $5 \%$ or $20 \% \mathrm{O}_{2}$, and four treatment groups grown under $20 \% \mathrm{O}_{2}$. The cleavage rate of each group was determined 48 to $72 \mathrm{~h}$ after parthenogenetic activation. The embryo cleavage rate did not differ between parthenotes cultured in $5 \% \mathrm{O}_{2}$ (positive control group) and $20 \% \quad \mathrm{O}_{2}$ (negative control group). Moreover, ginsenoside Rg1 had no significant effect on the embryo cleavage rate (Table 2). The rate of blastocyst development was analyzed $168 \mathrm{~h}$ after parthenogenetic activation, and there were no significant differences between the positive and negative control groups. Furthermore, treatment with ginsenoside $\mathrm{Rg} 1$ did not significantly alter the blastocyst formation rate (Table 2). These results demonstrate that $\mathrm{O}_{2}$ concentration and ginsenoside $\mathrm{Rg} 1$ treatment do not affect cleavage or blastocyst formation rates in porcine parthenotes cultured in vitro.

Effects of $\mathrm{O}_{2}$ concentration and ginsenoside $\mathrm{Rg} 1$ treatment on total blastocyst cell number and rate of apoptosis

The total number of blastocyst nuclei was determined by Hoechst 33342 staining $168 \mathrm{~h}$ after parthenogenetic activation. Apoptotic cell rate was subsequently calculated using a TUNEL assay. The total number of blastocyst cells was significantly higher in the positive control group than the negative control group. Treatment with ginsenoside Rg1 (20 and $50 \mu \mathrm{g} / \mathrm{mL}$ ) significantly increased cell number 
Table 2. Cleavage and blastocyst formation rates ${ }^{1}$

\begin{tabular}{lcccccc}
\hline $\mathrm{O}_{2}$ & Section $(\mu \mathrm{g} / \mathrm{mL})$ & Total & Cleavage (no.) & $(\% \pm \mathrm{SEM})^{2}$ & Blastocyst (no.) $\left.^{(\% \pm S E M}\right)^{3}$ \\
\hline $20 \%$ & 0 & 120 & 104 & $86.67 \pm 2.36$ & 54 & $45.00 \pm 3.97$ \\
& 5 & 120 & 106 & $88.33 \pm 0.96$ & 59 & $49.17 \pm 3.15$ \\
& 10 & 120 & 109 & $90.83 \pm 2.85$ & 54 & $45.00 \pm 2.89$ \\
& 20 & 120 & 106 & $88.33 \pm 0.96$ & 60 & $50.00 \pm 3.04$ \\
$5 \%$ & 50 & 120 & 106 & $88.33 \pm 2.15$ & 54 & $45.00 \pm 3.19$ \\
\hline
\end{tabular}

SEM, standard error of the mean.

${ }^{1}$ All of the experiments were replicated four times. There were no significant differences between groups.

${ }^{2}$ Normal cleaved embryos at the two-cell and four-cell stage of development were selected 48 to $72 \mathrm{~h}$ after parthenogenetic activation.

${ }^{3}$ Blastocyst formation rate was calculated $168 \mathrm{~h}$ after parthenogenetic activation.

compared to the negative control group (Figures 1 and 2A). The rate of blastocyst cell apoptosis was significantly lower in the positive control group than the negative control group. In addition, ginsenoside $\operatorname{Rg} 1$ treatment $(10$ and $20 \mu \mathrm{g} / \mathrm{mL})$ significantly decreased DNA fragmentation compared to the negative control group (Figures 1 and 2B). Treatment with $5 \mu \mathrm{g} / \mathrm{mL}$ ginsenoside had no effect on cell number or apoptotic cell rate, and treatment with $10 \mu \mathrm{g} / \mathrm{mL}$ had no effect on total cell number, but decreased the rate of apoptosis. In contrast, treatment with $50 \mu \mathrm{g} / \mathrm{mL}$ increased the total cell number, but had no effect on apoptosis (Figure 2). Therefore, high concentrations of ginsenoside $\operatorname{Rg} 1$ (50 $\mu \mathrm{g} / \mathrm{mL}$ ) do not reduce apoptosis, whereas medium concentrations $(10,20 \mu \mathrm{g} / \mathrm{mL})$ do. In addition, high concentrations of ginsenoside ( 20 and $50 \mu \mathrm{g} / \mathrm{mL}$ ) increase cell number, whereas lower concentrations do not. These results suggest that ginsenoside may be toxic at high concentration (50 $\mu \mathrm{g} / \mathrm{mL})$ (Liu et al., 2006). Together, these data demonstrate that $20 \mu \mathrm{g} / \mathrm{mL}$ is the best treatment concentration because it increased total cell number and decreased the rate of apoptosis.

\section{Changes in mRNA expression levels}

Due to the results of the above experiments, $20 \mu \mathrm{g} / \mathrm{mL}$ ginsenoside was selected for subsequent experiments. Genes related to intrinsic apoptosis pathways were selected
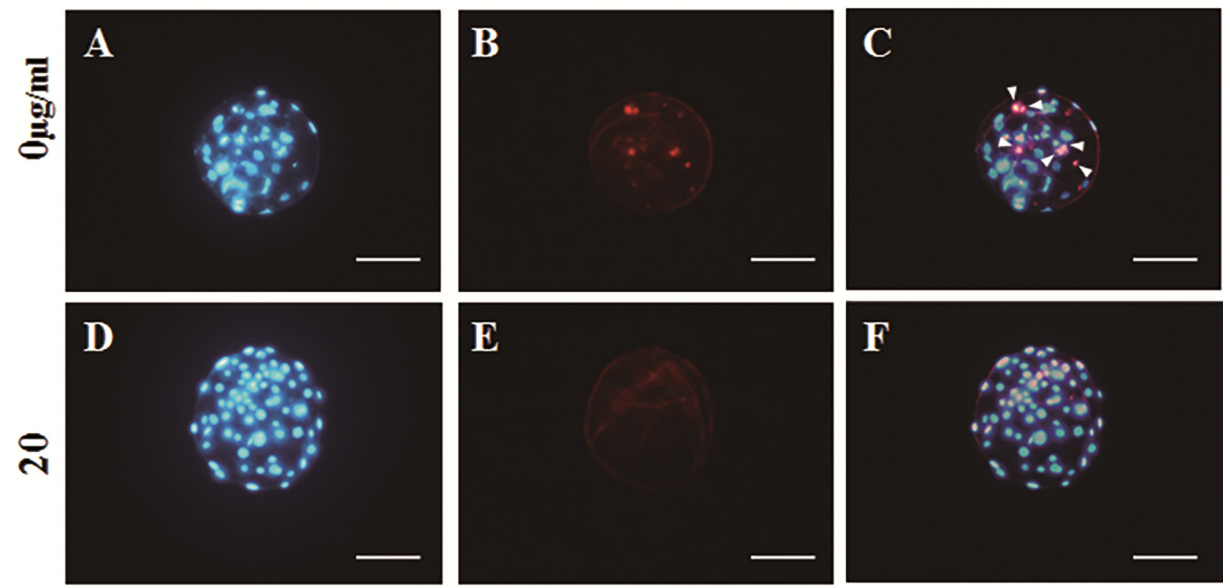

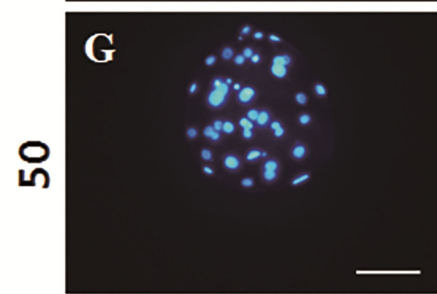

Total Nuclei

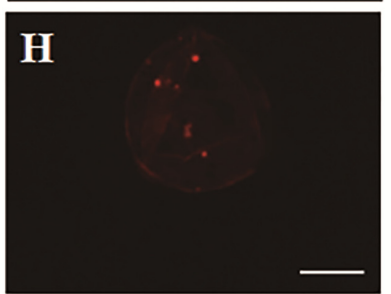

Apoptotic Nuclei

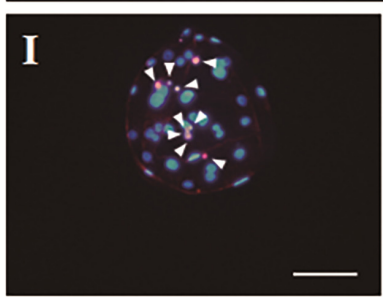

Merge

Figure 1. Apoptosis in treated and untreated parthenogenetic-activated blastocysts grown in high-oxygen conditions. To verify the effects of ginsenoside $\operatorname{Rg} 1$ on apoptosis, cultured parthenotes were separated into untreated ( $0 \mu \mathrm{g} / \mathrm{mL}$ [A to C]), and ginsenoside Rg1-treated groups $(20 \mu \mathrm{g} / \mathrm{mL}$ [D to $\mathrm{F}$ ], $50 \mu \mathrm{g} / \mathrm{mL}$ [G to I]). Blastocyst apoptosis rate was measured through an in situ cell death terminal deoxynucleotidyltransferase (TdT)-mediated deoxy-uridine nick-end labeling (TUNEL) assay. Blastocysts cultured for $168 \mathrm{~h}$ were stained by nuclear staining (left panels: total nuclei [A, D, G]; middle panels: apoptotic-nuclei [B, E, H]; right panels: merged figures, nuclei stained with blue and red simultaneously are marked by arrows [C, F, I]). Scale bars $=100 \mu \mathrm{m}$. 


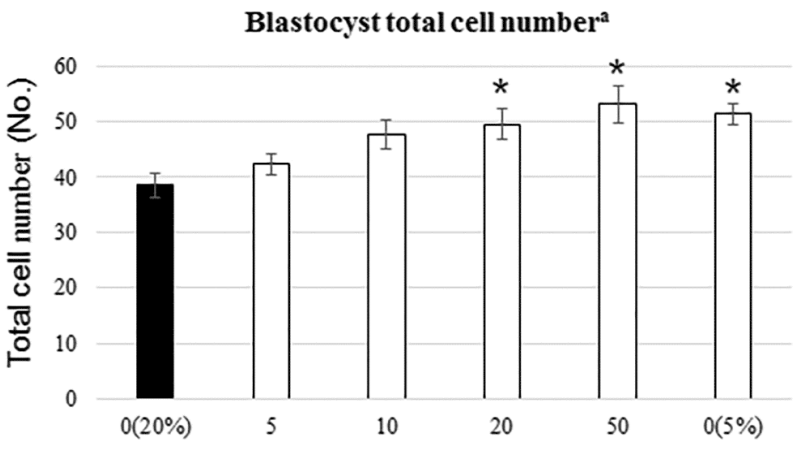

(A)

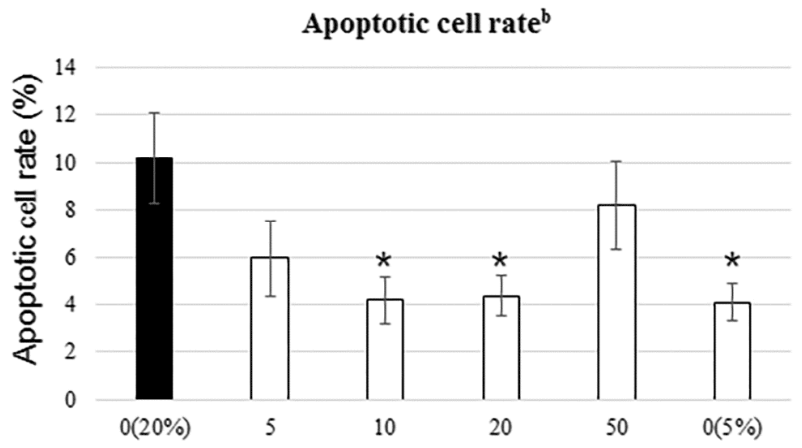

(B)

Figure 2. Total blastocyst cell numbers and apoptosis rates. The total number of nuclei in blastocysts cultured for $168 \mathrm{~h}$ after parthenogenetic activation was determined by Hoechst 33342 staining. Apoptotic cell rate was calculated using a terminal deoxynucleotidyltransferase (TdT)-mediated deoxy-uridine nick-end labeling (TUNEL) assay. (A) The total cell number in the positive control and treated groups ( 20 and $50 \mu \mathrm{g} / \mathrm{mL}$ ) was significantly increased compared to the negative control group. (B) The rate of apoptosis in blastocyst cells was significantly decreased in treated groups (10 and $20 \mu \mathrm{g} / \mathrm{mL}$ ) compared to the negative control group. An asterisk indicates statistical significance $(\mathrm{p}<0.05)$. The numbers $(5,10,20$, and 50$)$ indicate the concentration of ginsenoside $\mathrm{Rg} 1 \mathrm{used}$ $(\mu \mathrm{g} / \mathrm{mL})$, and $0(20 \%)=$ negative control, $0(5 \%)=$ positive control. ${ }^{a}$ Blastocyst counts were replicated four times. ${ }^{\mathrm{b}}$ Measurements of apoptotic cell rate were replicated three times.

to investigate the antioxidative effects of ginsenoside $\operatorname{Rg} 1$. Treatment with ginsenoside $\mathrm{Rg} 1$ did not change the expression of apoptosis-related genes including $\mathrm{Bcl}-2$ homologous antagonist/killer (BAK1), B-cell lymphomaextra large (Bcl-xL, BCL2-like 1 isoform 1), Caspase 3 (CASPASE3), and tumor protein p53 (TP53) compared to the negative control group. In addition, there were no differences in the expression of $B A K 1, B c l-x L, T P 53$, and CASPASE 3 between the positive and negative control groups (Figure 3A). Additional genes involved in metabolic processes were also examined. The expressions of Carnitine palmitoyltransferase 1B (CPT1B) and mechanistic target of rapamycin $(m T O R)$, metabolism-related genes, were similar

\section{Apoptosis}

Relative mRNA expression levels

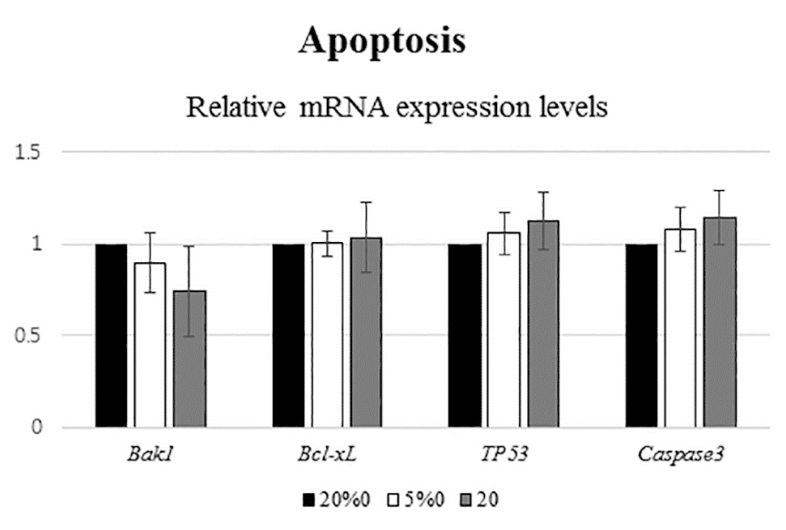

(A) between the groups; however, ginsenoside treatment increased the expression of glucose transporter 1 (GLUT1), a glucose transporter (Figure 3B).

\section{DISCUSSION}

We investigated the effects of ginsenoside $\mathrm{g} 1$ treatment on in vitro-produced preimplantation embryos grown in high-oxygen conditions, which are of lower quality than in vivo-produced embryos (Mateusen et al., 2005). There are many differences between in vivo and in vitro environments, including differences in ROS. To control for these differences, various experiments designed to protect

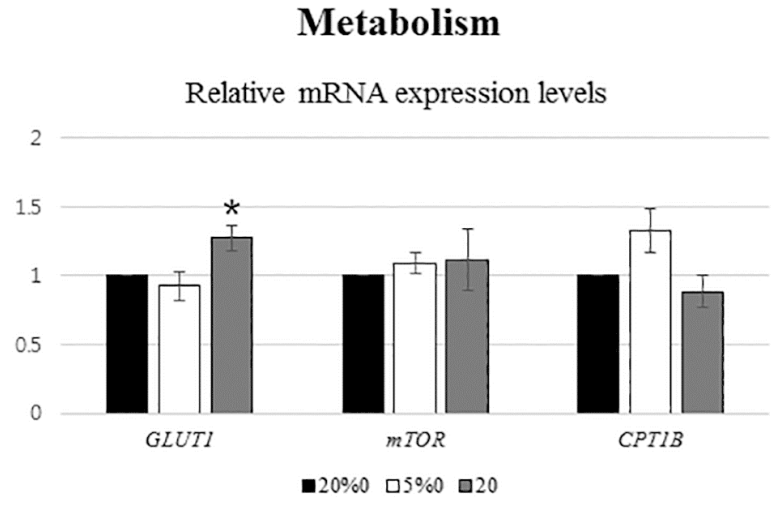

(B)

Figure 3. Relative mRNA expression of apoptotic- and metabolic-related genes. The mRNA levels of apoptosis regulatory genes (Bcl-2 homologous antagonist/killer, B-cell lymphoma-extra large, tumor protein p53, and Caspase 3) and metabolism regulatory genes (glucose transporter 1, mechanistic target of rapamycin, and carnitine palmitoyltransferase 1B) were analyzed in parthenogenetic-activated blastocysts cultured with or without ginsenoside Rg1. (A) Expression of apoptosis-related genes did not significantly differ between groups. (B) Of the genes related to metabolism, only GLUT1 was significantly different between the treated and control groups. Results are displayed as the fold change in the positive control (white) and treatment groups $(20 \mu \mathrm{g} / \mathrm{mL}$, gray) relative to the negative control group (black). Experiments were replicated three times. An asterisk indicates statistical significance $(\mathrm{p}<0.05)$. 
embryos from oxidative stress have been performed, including co-culture systems (Menezo et al., 1990), decreasing light exposure (Goto et al., 1993), and antioxidant treatments (Kitagawa et al., 2004; Lee et al., 2010a). Ginsenoside Rg1 is a natural antioxidant that activates internal antioxidant enzymes and scavenges free radicals (Deng and Zhang, 1991). It also stimulates glucose uptake through two pathways (Shang et al., 2008; Lee et al., 2010b). However, its effects on porcine embryo development have not yet been examined.

Apoptosis involves various pathways, including extrinsic, intrinsic, and perforin/granzyme pathways. Of these, the intrinsic pathway is induced by hazardous factors such as radiation, toxins, hypoxia, hyperthermia, viral infections, and free radicals (Elmore, 2007). BAK1, Bcl-xL, $C A S P A S E 3$, and TP53 are known regulators of apoptosis, and are related to the intrinsic mitochondrial apoptosis pathway. The Bcl-2 family controls apoptotic mitochondrial events (Cory and Adams, 2002); BAK1 and Bcl-xL have roles in pro- and anti-apoptotic signaling, respectively (Elmore, 2007); Caspase 3 acts during the apoptosis execution phase by initiating DNA fragmentation (Stennicke and Salvesen, 1998); and TP53 is a cell cycle regulator that can activate apoptosis (Fridman and Lowe, 2003). Despite their importance in apoptosis, their expressions were not altered by ginsenoside treatment, and did not differ between the positive and negative control groups. These results indicate that the antioxidant effect of ginsenoside on embryos is not related to the intrinsic apoptosis pathway (Figure 3A). Major metabolic pathways consisting of various specific pathways utilize energy substrates including glucose, amino acids, and fatty acids to produce ATP, and these pathways are important for early embryo development (Lane and Gardner, 1996). During embryo development, GLUT1 is the major transporter responsible for glucose uptake in the preimplantation embryo (Morita et al., 1992), and glucose is the predominant energy source during the blastocyst stage (Brison and Leese, 1991). mTOR participates in the initiation of protein synthesis, growth, and the first cell division in early development and trophoblast behavior (Land et al., 2014). CPT1B is involved in oxygen uptake as well as beta-oxidation and degradation of fatty acids (Gentile et al., 2004). The results from this study show that, compared to positive and negative controls, $20 \mu \mathrm{g} / \mathrm{mL}$ ginsenoside increased GLUT1 expression. Because high levels of GLUT1 correlate with increased glucose uptake (Kumar et al., 2015), these data indicate that glucose uptake was increased in ginsenoside-treated embryos. Ginsenoside stimulates glucose uptake through two pathways (Shang et al., 2008; Lee et al., 2010b), including the insulin signaling pathway by promoting the activation of both GLUT1 and
GLUT4 (Shang et al., 2008). Previous studies have also shown that in mouse preimplantation embryos, glucose uptake can affect total cell number, but not blastocyst formation rates (Martin and Leese, 1995). The results of the present study correspond well with previous studies performed in mice. Two other studies have reported that in human and porcine embryo, glucose uptake is minimal during early embryo developmental stage and is increased rapidly after 8-cell stage (Conaghan et al., 1993). Glucose also did not affect the rate of blastocyst formation (Hagen et al., 1991). Thereby, ginsenoside Rg1 treatment, which increases glucose uptake did not affect early embryo development (e.g., embryo cleavage rate and blastocyst formation rate).

Taken together, our data indicate that treatment with 20 $\mu \mathrm{g} / \mathrm{mL}$ ginsenoside $\mathrm{Rg} 1$ can increase the total number of blastocyst cells and decrease the apoptotic cell rate in embryos grown in high-oxygen conditions. Although the TUNEL assay showed changes in the apoptotic rate, no differences in apoptosis-related gene expression were found between the treated and untreated groups. However, ginsenoside treatment did increase GLUT1 mRNA expression, indicating increased glucose uptake, which may function to counteract damage from ROS. Thus, ginsenoside $\mathrm{Rg} 1$ can improve embryo quality by increasing glucose uptake in high-oxygen conditions. Previous studies have focused on decreasing ROS by treatment with various antioxidants to improve embryo development; however, this study shows that increasing glucose uptake can also improve embryo quality by protecting the cells from oxidative stress in high-oxygen conditions. Therefore, these results suggest that stimulating metabolic processes may be a potential method for reducing oxidative stress during in vitro culture of embryos.

\section{CONFLICT OF INTEREST}

We certify that there is no conflict of interest with any financial organization regarding the material discussed in the manuscript.

\section{ACKNOWLEDGMENTS}

This work was supported by the Next-generation BioGreen 21 Program (PJ0113002015), Rural Development Administration, Republic of Korea.

\section{REFERENCES}

Brison, D. R. and H. J. Leese. 1991. Energy metabolism in late preimplantation rat embryos. J. Reprod. Fertil. 93:245-251.

Chen, X. C., Y. G. Zhu, L. A. Zhu, C. Huang, Y. Chen, L. M. Chen, F. Fang, Y. C. Zhou, and C. H. Zhao. 2003. Ginsenoside Rg1 
attenuates dopamine-induced apoptosis in PC12 cells by suppressing oxidative stress. Eur. J. Pharmacol. 473:1-7.

Conaghan, J., A. H. Handyside, R. M. L. Winston, and H. J. Leese. 1993. Effects of pyruvate and glucose on the development of human preimplantation embryos in vitro. J. Reprod. Fertil. 99:87-95.

Cory, S. and J. M. Adams. 2002. The Bcl2 family: regulators of the cellular life-or-death switch. Nat. Rev. Cancer 2:647-656.

Deng, H. L. and J. T. Zhang. 1991. Anti-lipid peroxilative effect of ginsenoside Rb1 and Rg1. Chin. Med. J. 104:395-398.

Elmore, S. 2007. Apoptosis: a review of programmed cell death. Toxicol. Pathol. 35:495-516.

Fridman, J. S. and S. W. Lowe. 2003. Control of apoptosis by p53. Oncogene 22:9030-9040.

Gentile, L., M. Monti, V. Sebastiano, V. Merico, R. Nicolai, M. Calvani, S. Garagna, C. A. Redi, and M. Zuccotti. 2004. Single-cell quantitative RT-PCR analysis of Cpt1b and Cpt2 gene expression in mouse antral oocytes and in preimplantation embryos. Cytogenet. Genome Res. 105:215221

Goto, Y., Y. Noda, T. Mori, and M. Nakano. 1993. Increased generation of reactive oxygen species in embryos cultured in vitro. Free Radic. Biol. Med. 15:69-75.

Guerin, P., S. El Mouatassim, and Y. Menezo. 2001. Oxidative stress and protection against reactive oxygen species in the pre-implantation embryo and its surroundings. Hum. Reprod. Update 7:175-189.

Hagen, D. R., R. S. Prather, M. M. Sims, and N. L. First. 1991. Development of one-cell porcine embryos to the blastocyst stage in simple media. J. Anim. Sci. 69:1147-1150.

Kenarova, B., H. Neychev, C. Hadjiivanova, and V. D. Petkov. 1990. Immunomodulating activity of ginsenoside $\mathrm{Rg} 1$ from Panax ginseng. Jpn. J. Pharmacol. 54:447-454.

Kitagawa, Y., K. Suzuki, A. Yoneda, and T. Watanabe. 2004. Effects of oxygen concentration and antioxidants on the in vitro developmental ability, production of reactive oxygen species (ROS), and DNA fragmentation in porcine embryos. Theriogenology 62:1186-1197.

Kumar, P., A. Verma, M. Kumar, S. De, R. Kumar, and T. K. Datta. 2015. Expression pattern of glucose metabolism genes correlate with development rate of buffalo oocytes and embryos in vitro under low oxygen condition. J. Assist. Reprod. Genet. 32:471-478.

Land, S. C., C. L. Scott, and D. Walker. 2014. mTOR signalling, embryogenesis and the control of lung development. Semin. Cell Dev. Biol. 36:68-78.

Lane, M. and D. K. Gardner. 1996. Fertilization and early embryology: Selection of viable mouse blastocysts prior to transfer using a metabolic criterion. Hum. Reprod. 11:19751978.
Lee, K., C. Wang, J. M. Chaille, and Z. Machaty. 2010. Effect of resveratrol on the development of porcine embryos produced in vitro. J. Reprod. Dev. 56:330-335.

Lee, M. S., J. T. Hwang, S. H. Kim, S. Yoon, M. S. Kim, H. J. Yang, and D. Y. Kwon. 2010. Ginsenoside Rc, an active component of Panax ginseng, stimulates glucose uptake in C2C12 myotubes through an AMPK-dependent mechanism. J. Ethnopharmacol. 127:771-776.

Liu, P., H. Yin, Y. Xu, Z. Zhang, K. Chen, and Y. Li. 2006. Effects of ginsenoside $\mathrm{Rg} 1$ on postimplantation rat and mouse embryos cultured in vitro. Toxicol. In Vitro 20:234-238.

Livak, K. J. and T. D. Schmittgen. 2001. Analysis of relative gene expression data using real-time quantitative PCR and the 2(Delta Delta C(T)) Method. Methods 25:402-408.

Lu, J. M., Q. Yao, and C. Chen. 2009. Ginseng compounds: an update on their molecular mechanisms and medical applications. Curr. Vasc. Pharmacol. 7:293-302.

Martin, K. L. and H. J. Leese. 1995. Role of glucose in mouse preimplantation embryo development. Mol. Reprod. Dev. 40:436-443.

Mateusen, B., A. Van Soom, D. G. Maes, I. Donnay, L. Duchateau, and A. S. Lequarre. 2005. Porcine embryo development and fragmentation and their relation to apoptotic markers: a cinematographic and confocal laser scanning microscopic study. Reprod. 129:443-452.

Menezo, Y. J., J. F. Guerin, and J. C. Czyba. 1990. Improvement of human early embryo development in vitro by coculture on monolayers of Vero cells. Biol. Reprod. 42:301-306.

Mook-Jung, I., H. S. Hong, J. H. Boo, K. H. Lee, S. H. Yun, M. Y. Cheong, I. Joo, K. Huh, and M. W. Jung. 2001. Ginsenoside $\mathrm{Rb} 1$ and $\mathrm{Rg} 1$ improve spatial learning and increase hippocampal synaptophysin level in mice. J. Neurosci. Res. 63:509-515.

Morita, Y., O. Tsutsumi, I. Hosoya, Y. Taketani, Y. Oka, and T. Kato. 1992. Expression and possible function of glucose transporter protein GLUT1 during preimplantation mouse development from oocytes to blastocysts. Biochem. Biophys. Res. Commun. 188:8-15.

Shang, W., Y. Yang, L. Zhou, B. Jiang, H. Jin, and M. Chen. 2008. Ginsenoside Rb1 stimulates glucose uptake through insulinlike signaling pathway in 3T3-L1 adipocytes. J. Endocrinol. 198:561-569

Shi, A. W., X. B. Wang, F. X. Lu, M. M. Zhu, X. Q. Kong, and K. J. Cao. 2009. Ginsenoside Rg1 promotes endothelial progenitor cell migration and proliferation. Acta Pharmacol. Sin. 30:299-306.

Stennicke, H. R. and G. S. Salvesen. 1998. Properties of the caspases. Biochim. Biophys. Acta 1387:17-31.

Xie, J. T., S. McHendale, and C. S. Yuan. 2005. Ginseng and diabetes. Am. J. Chin. Med. 33:397-404. 